\title{
ERRATUM
}

\section{Chapter 12 \\ Toward Individualistic Cooperative Play: A Systematic Analysis of Mobile Social Games in Japan}

\author{
Akiko Shibuya, Mizuha Teramoto, and Akiyo Shoun \\ (C) Springer Science+Business Media Dordrecht 2017 \\ D.Y. Jin (ed.), Mobile Gaming in Asia, Mobile Communication in Asia: Local \\ Insights, Global Implications, DOI 10.1007/978-94-024-0826-3_12
}

DOI 10.1007/978-94-024-0826-3_14

The figure 12.1 in chapter 12 "Toward Individualistic Cooperative Play: A Systematic Analysis of Mobile Social Games in Japan" has been updated. 